\title{
Effect of Cellulose Reducing Ends on the Reinforcing Capacity of Powdered Cellulose in Polypropylene Composites
}

\author{
Mohammadali Azadfar ${ }^{1,2, *}$, Max R. Graham ${ }^{1}$ and Michael P. Wolcott ${ }^{1}$ D \\ 1 Composite Materials and Engineering Center, Voiland College of Engineering and Architecture, \\ Washington State University, P.O. Box 645815, Pullman, WA 99164-5815, USA; \\ max.graham@wsu.edu (M.R.G.); wolcott@wsu.edu (M.P.W.) \\ 2 Wood Tech. Center, Division of Environmental \& Renewable Resources, \\ College of Agriculture and Technology, State University of New York, P.O. Box 901, Morrisville, \\ NY 13408, USA \\ * Correspondence: mohammadali.azadfar@wsu.edu; Tel.: +1-315-684-6032
}

Received: 8 September 2019; Accepted: 6 November 2019; Published: 9 November 2019

\begin{abstract}
Powdered cellulose-reinforced (20 wt\%) polypropylene composites were prepared by melt compounding and subsequent injection moldings. We assessed the effect of cellulose reducing ends on the capacity of powdered cellulose to reinforce polypropylene composites after seven days exposure to air circulation during the conditioning of samples. Tensile tests on the composites were performed at $5.08 \mathrm{~mm} / \mathrm{min}$. Fourier transform infrared spectroscopy revealed some changes that occurred within the composites by demonstrating a practical decrease in $-\mathrm{C}=\mathrm{O}\left(1744 \mathrm{~cm}^{-1}\right)$ absorption band intensity. A thermogravimetric analysis indicated differences within the thermal behavior of the prepared composites, showing a higher onset of degradation. Scanning electron microscopy of the fracture areas, together with load-extension curves, further characterized the development of interfacial cellulose/matrix adhesion as well as the brittle and ductile behavior of the composites. The results indicate that the thermal and tensile properties of powdered cellulose/polypropylene are improved by decreasing the amount of cellulose reducing ends in the system.
\end{abstract}

Keywords: powdered cellulose; reducing ends; polypropylene; reinforcement

\section{Introduction}

One of the greatest challenges in the application of thermoplastic content lignocellulosic composites relates to compounding, or blending [1]. Compounding is defined as the feeding and dispersion of the lignocellulosic component throughout the thermoplastic matrix [2]. Polypropylene (PP), also known as polypropene, is a thermoplastic polymer that is used in a wide variety of applications, due to advantages such as its easy processability and low production cost [3]. Lignocellulosic/PP composites are extensively used as materials for automotive interior panels, building composites, and various electric and industrial components [4].

In the case of high thermoplastic content composites such as lignocellulosic/PP composites, problems arise from the difference in the bulk density of the two components [2]. In order to simplify the issues related to bulk density, the bulk density of a selected component should be as close to that of the thermoplastic component as possible [5]. Lignocellulosics may be used in fiber or particle/flour forms for blending. The bulk densities of lignocellulosics range from low (fibers) to high (particles/flour), indicating that particles and flour are more compatible for blending with thermoplastics rather than fibers as their bulk densities are closer to that of the thermoplastic [5]. 
As the most abundant lignocellulosic component found in nature, cellulose is increasingly being utilized for thermoplastic composite reinforcement [6,7]. Cellulose is a rigid, highly crystalline, and linear homopolymer comprised of basic monomeric unit d-glucose, which links the carbons (C-1 and C-4) of adjacent glucose units through $\beta-1,4$ glycosidic bonds, to form a long cellulosic chain with both amorphous and crystalline regions [8]. The bulk density of the cellulosic fibers can be adjusted by disrupting their crystalline structure and glycosidic bonds using environmentally friendly pulverization methods, in order to obtain cellulosic particles or powder [9]. The glucose C-1 end has reducing properties, while the glucose end group with a free $\mathrm{C}-4$ hydroxyl group is non-reducing. In intact cellulose, anomeric carbons (C-1) are restricted by the glycosidic bonds and therefore have no reducing properties [10]. The emergence of reducing ends with aldehyde functional groups in the cellulose, is attributed to the breakage of cellulose chains during pulverization and the mechanical cleavage of the glycosidic bonds as illustrated in Scheme 1 [11].

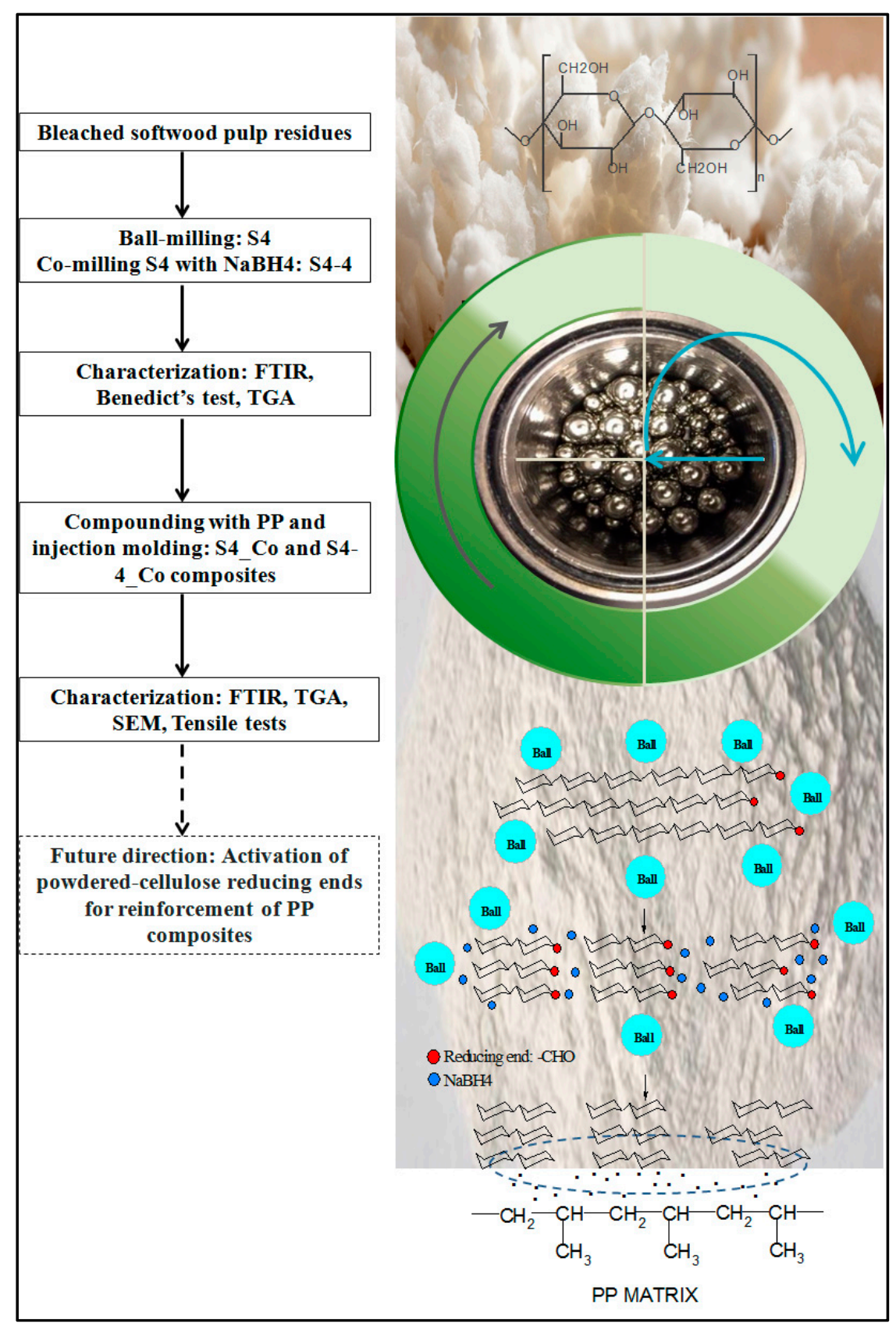

Scheme 1. Schematic illustration of the bull milling process. 
The presence of functional groups, such as aldehyde, carboxyl, and their combinations, can facilitate numerous chemical reactions of cellulose, leading to new molecular structures and properties [12-18]. Moreover, after blending cellulose with thermoplastics, cellulose functional groups may still influence the performance of the final composites, due to various processing parameters and environmental factors such as the oxidative conditions [19]. Several attempts have previously been made to address this issue. It has been proposed that the presence of coupling agents, stabilizers, natural fibers, and other components containing oxygenated species in the polypropylene matrix can influence the properties of the final composites due to the fact that these are more susceptible to oxidation than polypropylene [20-22].

It appears that aldehyde functional groups such as active oxygenated species may be rather specific in their effect on the oxidation behavior of cellulosic materials under different oxidative conditions. However, the effect of the reducing end aldehyde groups present in the powdered cellulose in reinforcing polypropylene composites, after seven days exposure to air circulation, and in accordance with standard procedures for the conditioning of plastic samples for testing, has not been described and is not well understood.

In the present work, we assessed the presence of reducing ends in powdered cellulose samples using Benedict's reagent. We prepared cellulose/PP composite specimens by compounding powdered cellulose samples with PP through twin-screw extrusion, followed by injection molding. These specimens were used to investigate the reinforcing abilities of the powdered cellulose samples in the PP composites, with particular attention to their cellulose reducing ends. In this regard, a series of analytical techniques was employed, including attenuated total reflectance Fourier transform infrared spectroscopy (ATR-FTIR), thermogravimetric analysis (TGA), scanning electron microscopy (SEM), and the ASTM standard test method for determining the tensile properties of plastics. Powdered cellulose samples were prepared by milling bleached softwood pulp residues through a lab-scale planetary ball mill. The obtained powdered cellulose samples were then co-milled with sodium borohydride as the reducing agent, in a completely dry environment (Scheme 1). Milling methods, such as ball milling, are typical mechanical techniques used to address important hurdles in cellulose processing [23,24]. Ball milling has the advantage of eliminating equipment corrosion and environmental toxicity, making it a viable option for deconstructing the robust crystalline structure of cellulose and decreasing its chain length in a sustainable manner [25].

The knowledge obtained as to the reinforcing abilities of powdered cellulose in PP composites may be used to improve the performance of composites and to economically promote its production for demanding applications.

\section{Experimental}

\subsection{Materials}

Bleached softwood fluff pulp, which is cellulose pulp (CP), was provided by the Weyerhaeuser company (Federal way, WA, USA). Our previous composition analysis also showed negligible lignin in the CP. The CP was stored in ambient conditions. Sodium borohydride powder ( $99 \%$ purity) was purchased from Sigma-Aldrich (Milwaukee, WI, USA). Benedict's reagent (a solution of citrate and sodium carbonate mixed with a solution of copper sulfate) was purchased from Sigma-Aldrich (Milwaukee, USA). Pure PP beads were kept in ambient conditions and used for compounding with the powdered cellulose. All the chemicals were used without further purification.

\subsection{Preparation of Powdered Cellulose through Ball Milling}

$\mathrm{CP}$ pulverization was conducted at ambient pressure and at room temperature using a planetary ball mill (PQ-N04 Gear Drive 4-Station, Across International), equipped with two $100 \mathrm{~mL}$ and two $50 \mathrm{~mL}$ steel jars (Figure 1). Each $100 \mathrm{~mL}$ jar was charged with 100 steel balls (Ø 6mm) and 16 steel balls (Ø $10 \mathrm{~mm}$ ). In addition, $50 \mathrm{~mL}$ steel jars were charged with 35 steel balls ( $66 \mathrm{~mm}$ ) and 10 steel balls 
(Ø $10 \mathrm{~mm}$ ). The CP was weighed and added to each jar at a ball-cellulose charge ratio of 40:1 and subsequently ball milled at $60 \mathrm{~min}$ and labeled S4. Additional ball milling was conducted to co-mill the S4 sample with sodium borohydride at $20 \mathrm{wt} \%$, which was labeled S4-4 (Table 1). The milling frequency throughout the experiment was $50 \mathrm{~Hz}$, in single-direction mode and at a rotation speed of $550 \mathrm{rpm}$. Sodium borohydride was washed out of the samples by mixing them with DI water, after which, the water was removed. The limited temperature increase resulting from this process was deemed to have a negligible influence on the powdered cellulose.

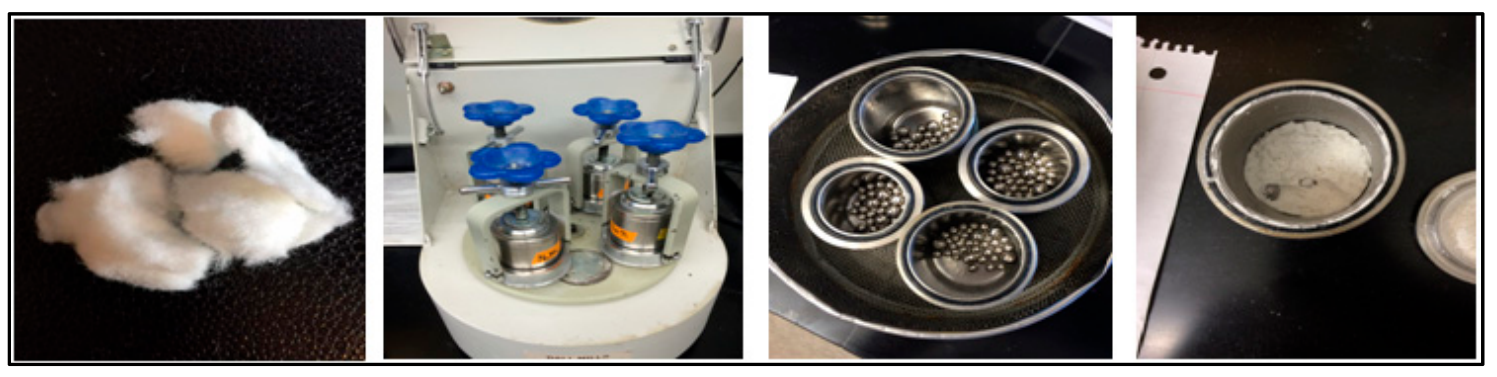

Figure 1. The cellulose pulp, ball mill, steel jars and balls, and powdered cellulose (left to right).

Table 1. Powdered cellulose samples prepared by ball milling.

\begin{tabular}{ccccc}
\hline Sample & Ball Milling (min) & Sample & Ball Milling (min) & $\mathbf{N a B H}_{\mathbf{4}}(\mathbf{w t} \%)$ \\
\hline S4 & 60 & $\mathrm{~S} 4-4$ & 10 & 20 \\
\hline
\end{tabular}

\subsection{Qualitative Determination of Powdered Cellulose Reducing Ends Using Benedict's Reagent}

A sample (100 mg) of CP and each type of powdered cellulose (S4 and S4-4) was mixed with DI water $(1 \mathrm{~mL})$ for $2 \mathrm{~min}$, using a vortex machine. Benedict's reagent test solution $(3 \mathrm{~mL})$ was then added to each sample tube and boiled in a water bath for $4 \mathrm{~min}$. The formation of reddish brown, brick-colored precipitate, indicated the presence of the reducing ends in the powdered cellulose as a result of ball milling.

\subsection{Compounding and Injection Molding}

Prior to extrusion, the powdered cellulose samples (S4 and S4-4) were dried in a convection oven at $85^{\circ} \mathrm{C}$ for $24 \mathrm{~h}$. A conical twin-screw compounder (HAAKE, Thermo Scientific Co., Karlsruhe, Germany) was used to prepare the powdered cellulose/PP blends. The screw speed was fixed, and the temperature of the barrel was set to $175^{\circ} \mathrm{C}$. The blended samples were formulated with a PP/powdered cellulose weight ratio of $40 / 10(20 \mathrm{wt} \%)$. Prior to injection, the blended samples were dried at $85^{\circ} \mathrm{C}$ for one day in a convection oven. Tensile specimens were prepared by compounding powdered cellulose samples S4 and S4-4 with PP, using a micro extruder (HAAKE MiniJet II, Thermo Scientific Co.) at a temperature of $175^{\circ} \mathrm{C}$ and mold temperature of $65^{\circ} \mathrm{C}$, and labeled S4_Co and S4-4_Co, respectively (Figure 2). Prior to testing, all molded test specimens were conditioned at $23{ }^{\circ} \mathrm{C}$ and $50 \%$ relative humidity for seven days, according to the ASTM D 638-14 and ASTM D 618.3022 standards. 


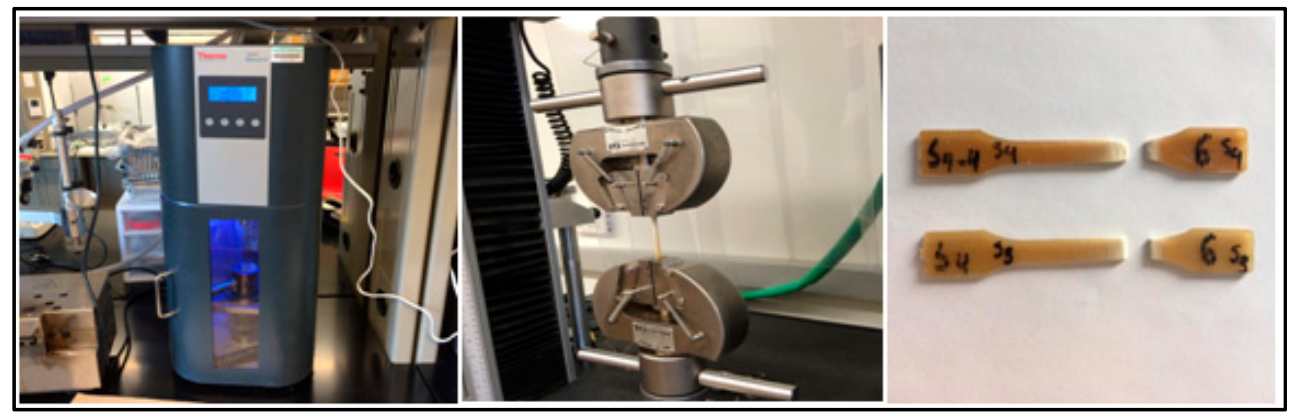

Figure 2. Injection molding and tensile testing machines, and the broken dog bone specimens after tensile testing (left to right).

\subsection{Characterization of Test Specimens}

After compounding and injection molding, all test specimens were characterized using ATR-FTIR, TGA, SEM, and tensile testing techniques.

\subsubsection{ATR-FTIR Specimen Analysis}

The FTIR analysis was performed to characterize the functional groups of the $\mathrm{CP}$ and powdered cellulose-reinforced PP composites (S4_Co and S4-4_Co). The FTIR spectra were obtained using an ATR-FTIR spectrophotometer (Shimadzu, Tokyo, Japan) with 64 scans. The ATR supplement was used to measure the changes in an internally reflected infrared beam, when the beam made contact with a sample with a typical penetration depth between $0.5 \mu \mathrm{m}$ and approximately $5 \mu \mathrm{m}$. Samples were then pressed onto the crystal surface of the ATR probe. Samples were analyzed for wavelengths of $3500-800 \mathrm{~cm}^{-1}$ at a resolution of $4 \mathrm{~cm}^{-1}$.

\subsubsection{Thermogravimetric Analysis}

Thermogravimetric measurements were performed using a Mettler Toledo TGA/DSC 1 apparatus. A Q600 instrument was used to scan all samples from $30-750{ }^{\circ} \mathrm{C}$, at a heating rate of $10^{\circ} \mathrm{C} / \mathrm{min}$ under a nitrogen atmosphere with a flow rate of $20 \mathrm{~mL} / \mathrm{min}$.

\subsubsection{Mechanical Properties and Scanning Electron Microscopy}

Mechanical properties were measured using a universal testing machine (Instron 4466, Norwood, MA, USA) with a $30 \mathrm{kN}$ load cell, at a crosshead rate of $5.08 \mathrm{~mm} / \mathrm{min}$. The initial strain was measured using a $12.7 \mathrm{~mm}$ extensometer. Testing was performed on the S4_Co and S4-4_Co composites, in accordance with the ASTM D 638-14 standard (Figure 2), and load-extension data were collected for each specimen. These data were used to calculate the percentage elongation at break, together with the tensile strength. In addition, scanning electron microscopy (FEI SEM Quanta 200F, Hillsboro, OR, USA) was used to study the fracture surfaces of composites S4_Co and S4-4_Co. Prior to examination, the fracture surfaces of the tensile specimens were sputter-coated with a thin layer of platinum in a vacuum chamber.

\section{Results and Discussion}

\subsection{Benedict Test Analysis}

The Benedict test was employed as a fast and qualitative measurement to assess the effect of ball milling on the emergence of reducing ends in powdered cellulose. Benedict's reagent contains copper in the +2 oxidation state, known as copper citrate. Copper citrate can oxidize reducing sugars, which contain a free aldehyde group. Benedict's reagent oxidizes the aldehyde groups present in the powdered cellulose samples, converting aldehydes to carboxylic groups [26]. When this reaction occurs, 
the copper (II) ions are reduced to copper (I) ions, causing a change in color to red when in contact with boiling water. When analyzing Benedict test results, a more intense red/brick color corresponds to an increased number of the aldehyde functional groups present in the sample. The S4 and CP samples, after mixing with DI water and prior to Benedict testing (pre-Benedict test), are shown in Figure 3a, while Figure $3 b$ shows the same samples after Benedict testing (post-Benedict test). Comparing the S4 and CP sample results, there is a significant increase in the intensity of the red/brick color of sample $\mathrm{S} 4$, as a consequence of ball milling. In contrast, the CP sample is not red following the Benedict test, indicating the influence of ball milling on the emergence of aldehyde functional groups in powdered cellulose. The results of Benedict testing on the S4 and S4-4 powdered cellulose samples are shown in Figure 3c. Benedict testing results in an intense red color in the case of sample S4, due to the aldehyde functional groups formed during ball milling. However, sample S4-4 is not red after Benedict testing, suggesting that sodium borohydride treatment effectively reduced the aldehyde functional groups of powdered cellulose (S4) that were formed during the ball milling process [27].

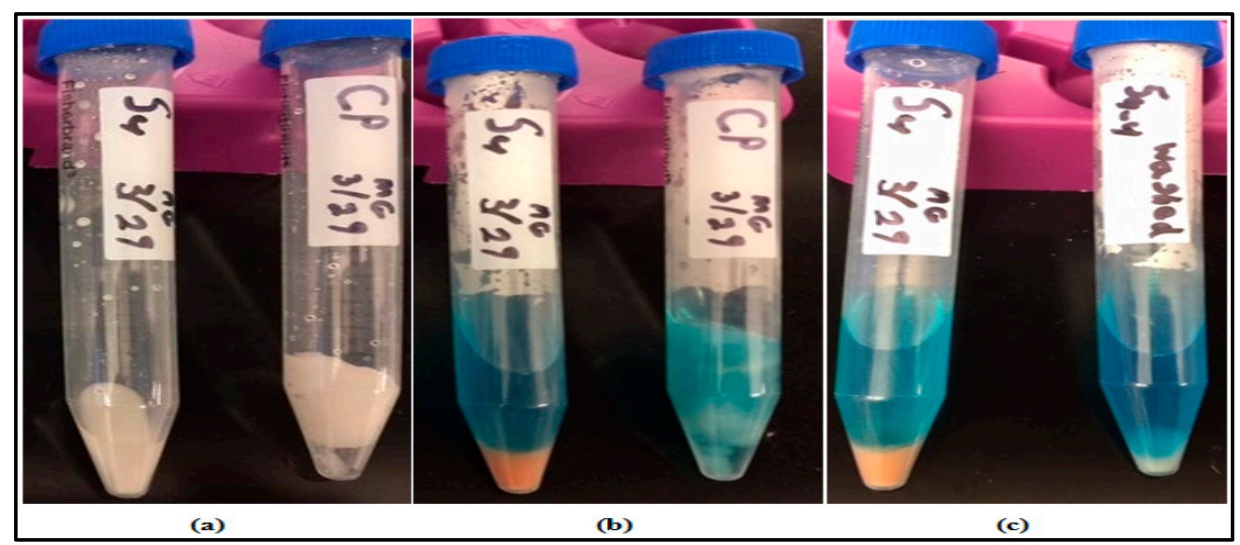

Figure 3. Pre-Benedict test-S4 and cellulose pulp (CP) samples (a); Post-Benedict test-S4 and CP samples (b); Post-Benedict test-S4 and S4-4 samples (c).

\subsection{ATR-FTIR Analysis}

The chemical functional groups of the CP, S4_Co, and S4-4_Co composites were characterized after exposure to air circulation for one week during the conditioning of samples for testing. A comparison of the FTIR spectra of the CP sample with those of the S4_Co and S4-4_Co composites is shown in Figure 4, and the corresponding band assignments are listed in Table 2 . The wavelength region $500-3500 \mathrm{~cm}^{-1}$ is presented in Figure 4, with the bands of interest identified by their wave number $\left(\mathrm{cm}^{-1}\right)$. The O-H stretching vibrations of hydrogen-bonded hydroxyl functional groups corresponded to the broad band at $3600-3100 \mathrm{~cm}^{-1}$ [28]. In the powdered cellulose-reinforced (20 $\mathrm{wt} \%$ ) polypropylene composites, the $\mathrm{O}-\mathrm{H}$ stretching vibrations of hydrogen-bonded hydroxyl functional groups are reduced, presumably due to the low content of cellulose $(20 \mathrm{wt} \%)$ and the predominant stretching vibrations of the $\mathrm{C}-\mathrm{H}$ $\left(-\mathrm{CH}_{3}\right.$ or $\left.-\mathrm{CH}_{2}^{-}\right)$in polypropylene. The band in the range $3000-2800 \mathrm{~cm}^{-1}$ is related to the stretching vibrations of the $\mathrm{C}-\mathrm{H}\left(-\mathrm{CH}_{3}\right.$ or $\left.-\mathrm{CH}_{2}-\right)$ in all samples [29]. The broad band in the region $1125-1004 \mathrm{~cm}^{-1}$ is the characteristic band for $\mathrm{C}-\mathrm{O}$ and the $\mathrm{C}-\mathrm{O}-\mathrm{C}$ stretching vibrations in cellulose [30]. In Figure 4, peaks in the ranges $2850-3000 \mathrm{~cm}^{-1}$ and $1377-1454 \mathrm{~cm}^{-1}$ correspond to the $\mathrm{CH}_{2}$ and $\mathrm{CH}_{3}$ vibrations in the composites. The weak peak located at $1166 \mathrm{~cm}^{-1}$ may be due to $\mathrm{CH}-\mathrm{CH}_{2}$ stretching and the rocking vibrations of $-\mathrm{CH}_{3}$ and $-\mathrm{CH}_{2}$, suggesting the presence of an isotactic band in PP [31,32]. There is a significant difference between the FTIR spectra of samples S4_Co and S4-4_Co. The band at $1744 \mathrm{~cm}^{-1}$ is attributed to the carbonyl $(-\mathrm{C}=\mathrm{O})$ stretching vibrations of carboxyl in the S4_Co sample. Kazayawoko and co-workers reported a carbonyl peak at $1730 \mathrm{~cm}^{-1}$ in wood fiber/PP systems [33]. Here, the carbonyl peaks are between $1739 \mathrm{~cm}^{-1}$ and $1741 \mathrm{~cm}^{-1}$ [34]. An absence of carbonyl peaks, or a decrease in their intensity, indicates that the aldehyde groups of the $\mathrm{S} 4$ sample are reduced by 
sodium borohydride (S4-4). Here, the S4-4_Co composite demonstrates negligible carboxyl group content compared to the S4_Co composite.

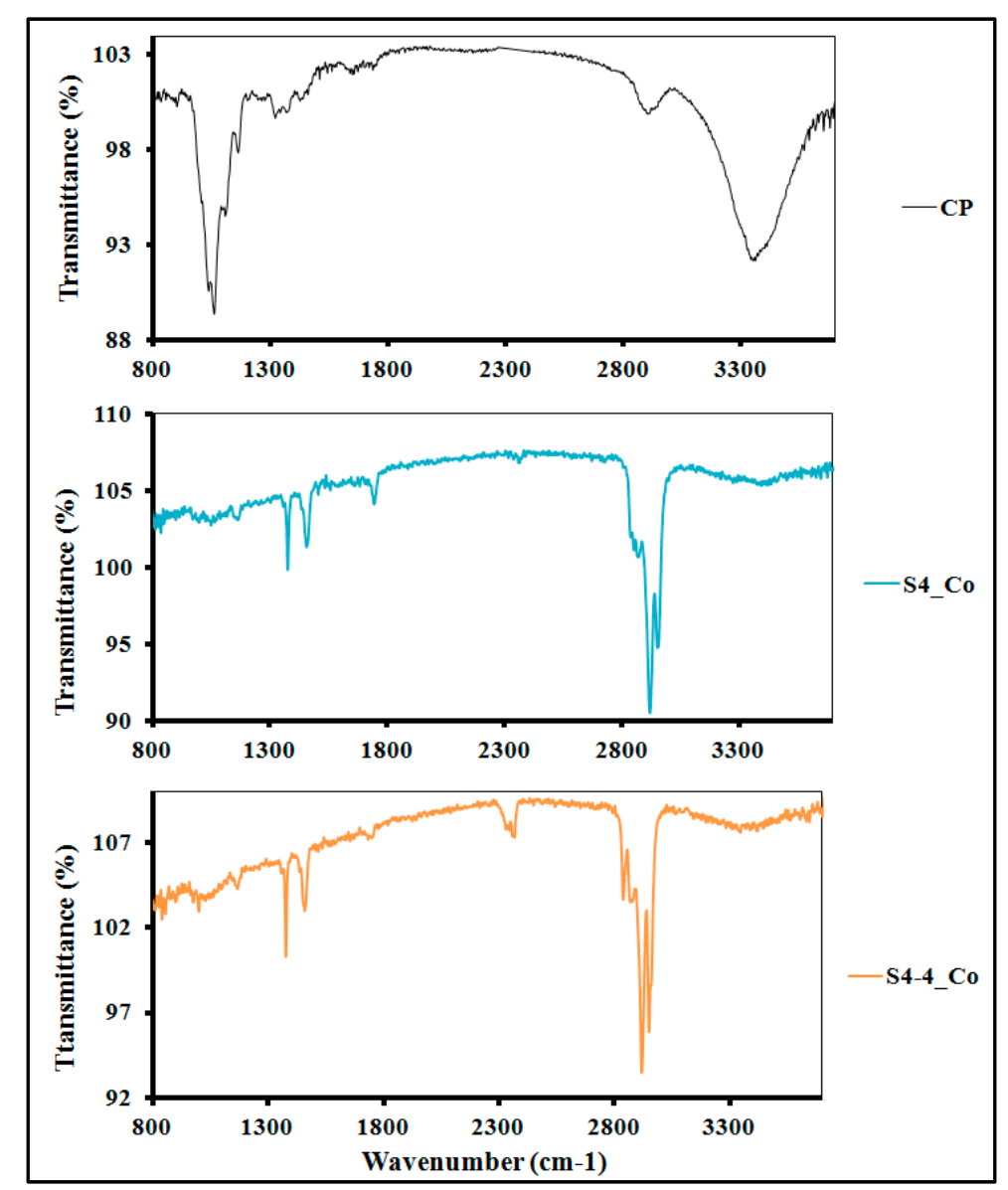

Figure 4. ATR-FTIR spectra of CP, S4_Co and S4-4_Co samples.

Table 2. Assignment of ATR-FTIR absorption bands of CP, S4_Co and S4-4_Co.

\begin{tabular}{|c|c|c|}
\hline \multirow{2}{*}{ Assignment } & \multicolumn{2}{|c|}{ Samples } \\
\hline & $\lambda\left(\mathrm{cm}^{-1}\right)$ & $\mathrm{T}(\%)$ \\
\hline $\mathrm{O}-\mathrm{H}$ stretching & $\begin{array}{l}3359 \text { (CP), } 3395 \text { (S4_Co), } \\
3346 \text { (S4-4_Co) }\end{array}$ & $\begin{array}{l}92.18 \text { (S2, strong), } 105.38 \text { (S4_Co, } \\
\text { weak), } 107.57 \text { (S4-4_Co, weak) }\end{array}$ \\
\hline $\begin{array}{l}\mathrm{C}-\mathrm{H} \text { asymmetric/symmetric } \\
\text { stretching }\end{array}$ & $\begin{array}{l}2898 \text { (CP), } 2921 \text { (S4_Co), } \\
2919 \text { (S4-4_Co) }\end{array}$ & $\begin{array}{l}99.90 \text { (CP, moderate), } 90.54 \text { (S4_Co, } \\
\text { strong), } 93.50 \text { (S4-4_Co, strong) }\end{array}$ \\
\hline $\mathrm{CH}_{2}, \mathrm{CH}_{3}$ asymmetric stretching & $\begin{array}{l}1377-1457 \text { (S4-Co), 1375-1457 } \\
\text { (S4-4_Co) }\end{array}$ & $\begin{array}{l}\text { 99.95-101.35 (S4_Co, strong), } \\
\text { 100.32-102.99 (S4-4_Co, strong) }\end{array}$ \\
\hline $\begin{array}{l}-\mathrm{CH}_{2} \text { and }-\mathrm{CH}_{3} \text { vibration of } \\
\text { the rocking }\end{array}$ & 1164 (S4_Co), 1166 (S4-4_Co) & $\begin{array}{l}103.13 \text { (S4_Co, weak), } \\
104.28 \text { (S4-4_Co, weak) }\end{array}$ \\
\hline $\mathrm{C}=\mathrm{O}$ stretching & 1744 (S4_Co), 1740 (S4-4_Co) & $\begin{array}{l}104.15 \text { (S4_Co, strong), } \\
107.27 \text { (S4-4_Co, weak) }\end{array}$ \\
\hline $\mathrm{C}-\mathrm{O} \& \mathrm{C}-\mathrm{O}-\mathrm{C}$ stretching & $\begin{array}{l}1059 \text { (CP), } 1049 \text { (S4_Co), } \\
1027 \text { (S4-4_Co) }\end{array}$ & $\begin{array}{l}89.36 \text { (CP, strong), } 102.77 \text { (S4_Co, } \\
\text { weak), } 103.58 \text { (S4-4_Co, weak) }\end{array}$ \\
\hline
\end{tabular}

\subsection{Thermogravimetric Analysis}

The TGA technique was used to study the effect of the aldehyde functional groups, with reducing ends in powdered cellulose, on the thermal stability of composites after specimen conditioning. 
TGA provides quantitative information on weight change during the heating process [35]. The TGA curves of the CP and the S4_Co and S4-4_Co composites are presented in Figure 5. Thermogravimetric analysis of the $\mathrm{CP}$ shows two degradation steps, which suggests the existence of more than one degradation process. The lower temperature loss step may correspond to the breaking of water linkages and moisture evaporation at approximately $100^{\circ} \mathrm{C}$, while the second temperature loss step with a maximum degradation rate at $300^{\circ} \mathrm{C}$ indicates the degradation of the whole cellulose polymer. All the composites exhibit two-stepped degradation due to the presence of powdered cellulose. The first degradation peak at approximately $320^{\circ} \mathrm{C}$ could be derived from the degradation of cellulosic components. The next degradation peak at $440^{\circ} \mathrm{C}$ is due to the degradation of the polymer matrix in the composites. In the case of powdered cellulose/PP composites, these results indicate that the maximum degradation rate is shifted to a higher temperature compared to that of $\mathrm{CP}$. These results suggest that the pulverization of $\mathrm{CP}$, and the consequent increase in the bulk density of the cellulose, improves the dispersion of powdered cellulose throughout the polymer matrix. This might be derived from the coating of PP around the cellulose components. However, treated and untreated powdered cellulose with sodium borohydride seems to have a different influence on the thermal degradation of the composites. The S4-4_Co composite exhibited an inhibition of heat degradation compared to the S4_Co composite. The $\mathrm{CP}$ with a lower degree of polymerization may contain numerous reducing ends, which may diminish sample stability against thermal degradation [18]. It has been stated that aldehyde groups have a range of different activation temperatures, on the basis of cellulose crystalline and non-crystalline regions, which may accelerate thermal degradation at lower temperatures, relative to cellulose that contains few reducing end groups [36]. Furthermore, the FTIR spectra (Figure 4) clearly reveal the carbonyl stretching vibrations of carboxyl in the S4 compounded PP composite (S4_Co), while this band practically disappeared in the S4-4_Co composite. This suggests that the aldehyde groups of the powdered cellulose compounded PP composite (S4_Co) are oxidized and converted to carboxyl groups during air-conditioning. The carboxylic groups produced in the S4_Co composite can be decarboxylated on heating, indicating their lower onset of degradation [19].

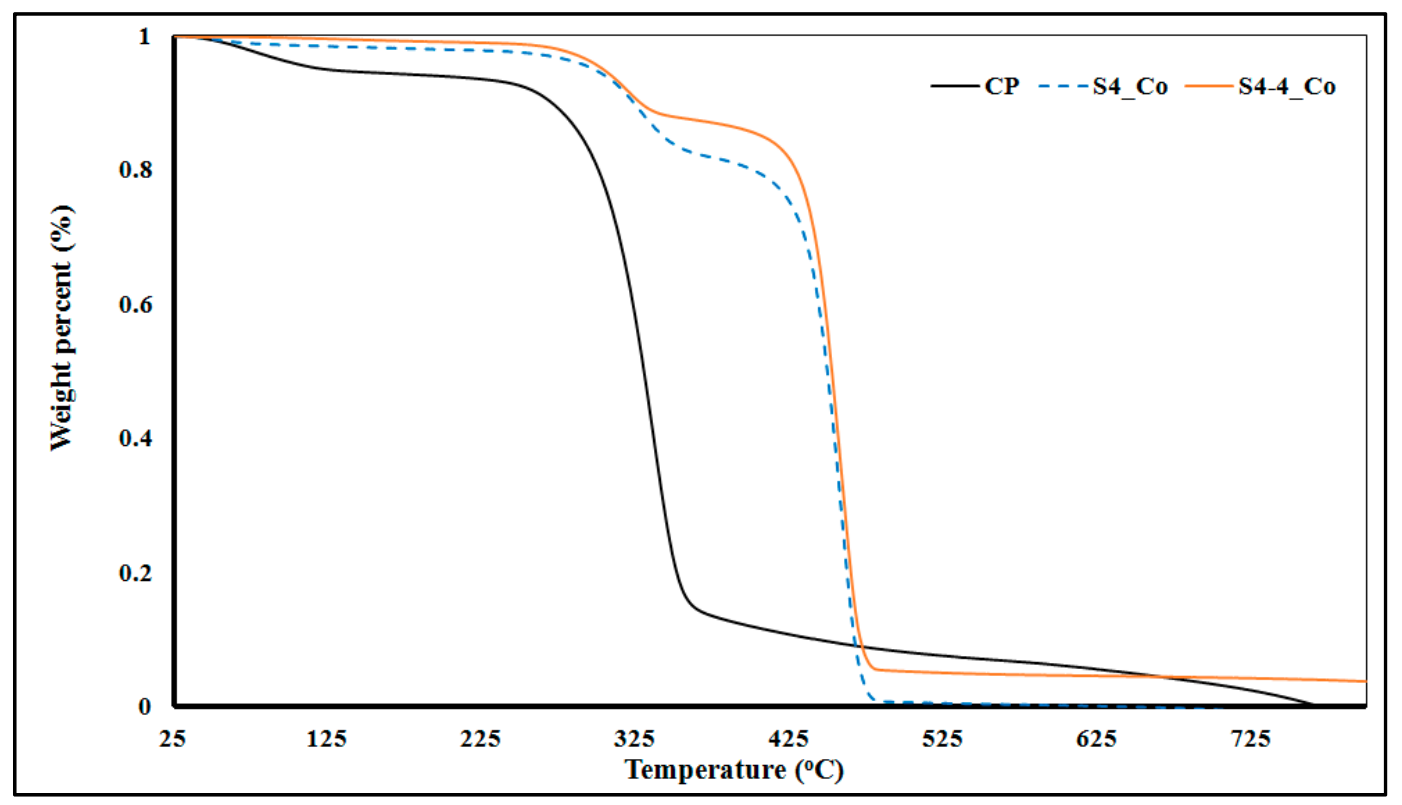

Figure 5. TGA curves of the S4-4_Co (upper line), S4_Co (middle line), and CP (bottom line).

\subsection{Mechanical Property Analysis and Scanning Electron Micrographs of Fracture Surfaces}

The changes in tensile strength and elongation at break for powdered cellulose ( $20 \mathrm{wt} \%)$ were assessed. The tensile testing and obtained elongation at break of S4, and S4-4 compounded with PP are illustrated in Figures 6 and 7. The average tensile strengths of these compounds are comparable, 
at 0.70 psi for S4_Co and 0.69 psi for S4-4_Co, indicating no significant change in the tensile strengths of composites containing powdered cellulose $(20 \mathrm{wt} \%)$. However, a decrease in tensile strength could be attributed to chain scission and the degradation of PP molecules [37]. It has been stated that the degradation of PP due to photo-oxidation causes a decrease in composite tensile strength [38]. It appears that the molecular structure of the PP is not degraded in either composite sample (S4_Co and S4-4_Co). The load-extension curves for S4_Co and S4-4_Co show an elongation at break that is significantly higher in the case of S4-4_Co. The percent elongation at break that is shown in Figure 7 for both compounded samples corroborates this result. The initial elongation at break of the S4-4_Co composite is much higher than that of the S4_Co composite. This is a consequence of the significantly lower ductility of the S4_Co composite compared to that of the S4-4_Co composite, suggesting the influence of aldehyde groups, which are abundant in the S4 sample, on the brittle behavior of the S4_Co composite. Miyazaki and co-workers reported that the tensile behavior of the fibrous cellulose/PP/MAPP composite was rather brittle, due to the inner reactive oxygenated groups of the MAPP [39].

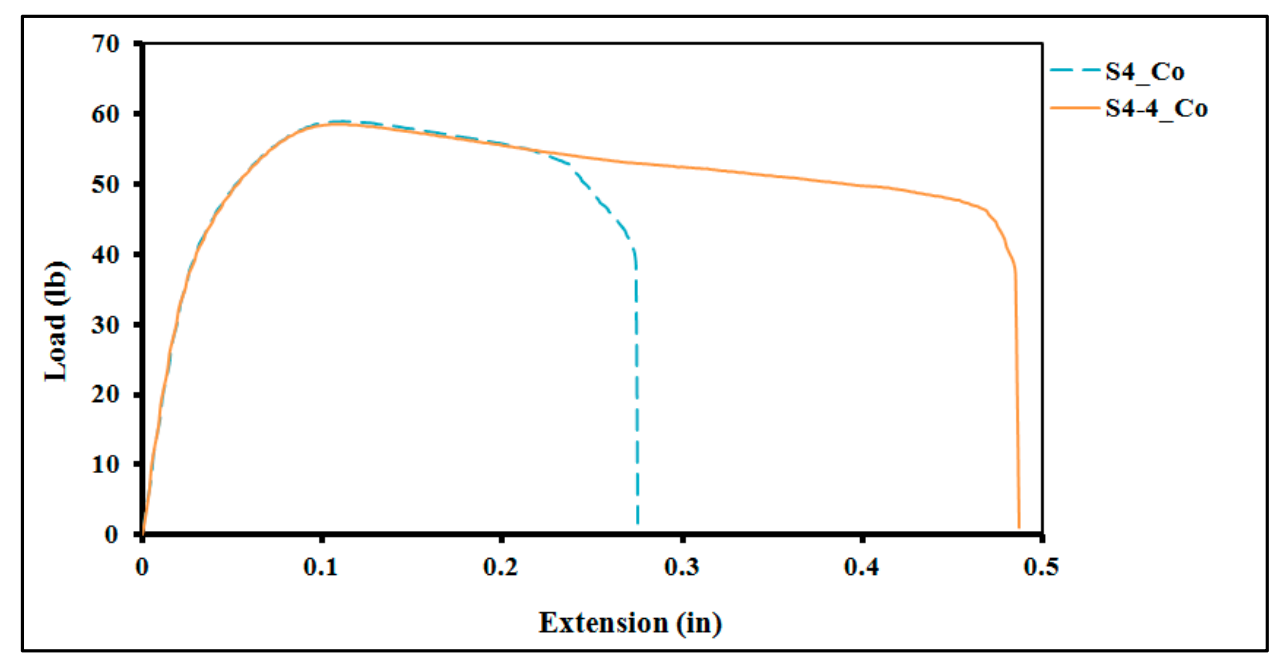

Figure 6. Load vs. extension curves of the S4_Co and S4-4_Co composites.

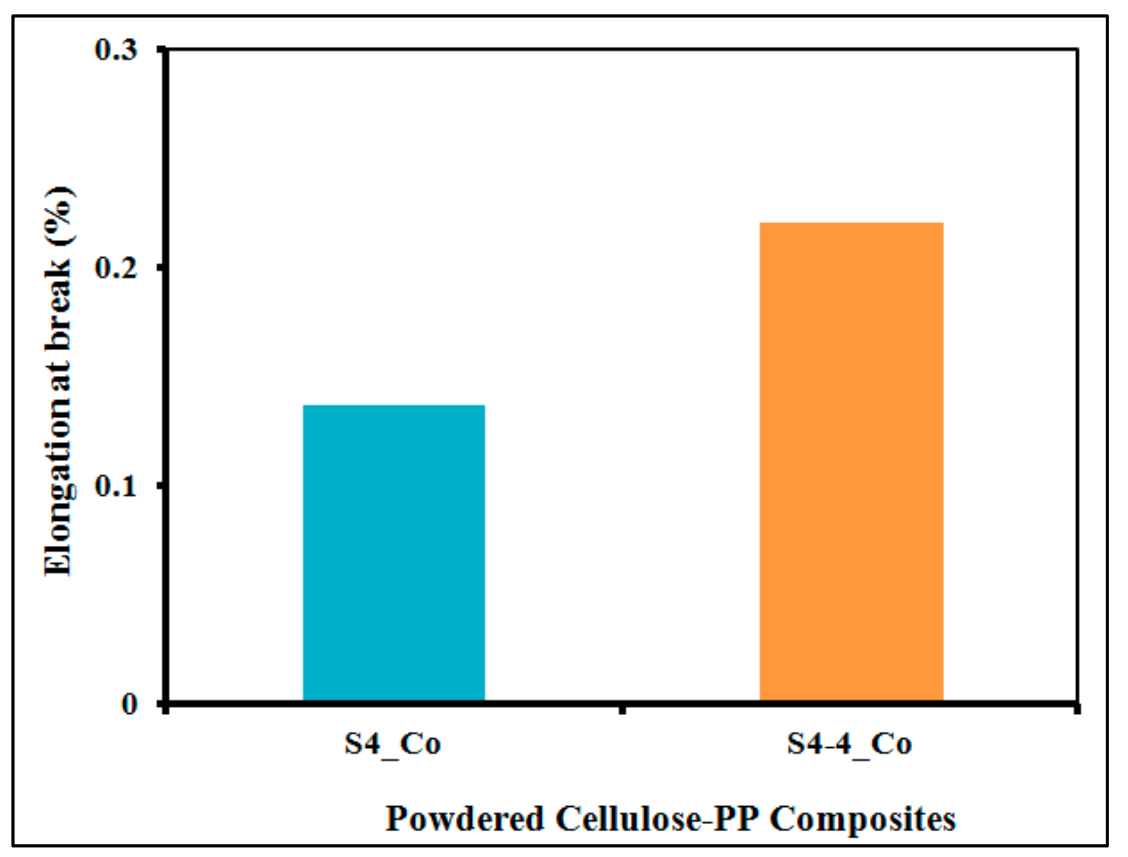

Figure 7. Percent elongation of the S4_Co and S4-4_Co composites. 
The scanning electron micrographs of the tensile fracture surfaces of composites S4-Co and S4-4_Co, extended at $5.08 \mathrm{~mm} / \mathrm{min}$ speed, are shown in Figure 8a,b, respectively. It can be seen that at $5.08 \mathrm{~mm} / \mathrm{min}$, the S4-Co composite shows a brittle behavior, which occurs through the formation of planes of crazes [40] (Figure 8a). However, in a study of the fracture surfaces of sawdust/PP composites, it has been observed that fracture surfaces show a predominant brittle mode at high testing speeds, e.g., $400 \mathrm{~mm} / \mathrm{min}$. The authors reported that a decrease in testing speed, e.g., approximately $5 \mathrm{~mm} / \mathrm{min}$, led to mixed modes of fracture, with brittle and ductile areas [41]. In the present work, this can be explained by the different mechanisms of break/fracture in the S4-4_Co and S4_Co composites. It is probable that these composites break at the polymer/natural fiber interface, which is usually the weakest point in these composites [42]. It might be suggested that the properties of the interface do not decay through degradation after compounding/blending. However, it is possible that the interfacial adhesion can be diminished by degradation following the formation of polar carbonyl groups in the cellulose, as revealed by FTIR (Figure 4).
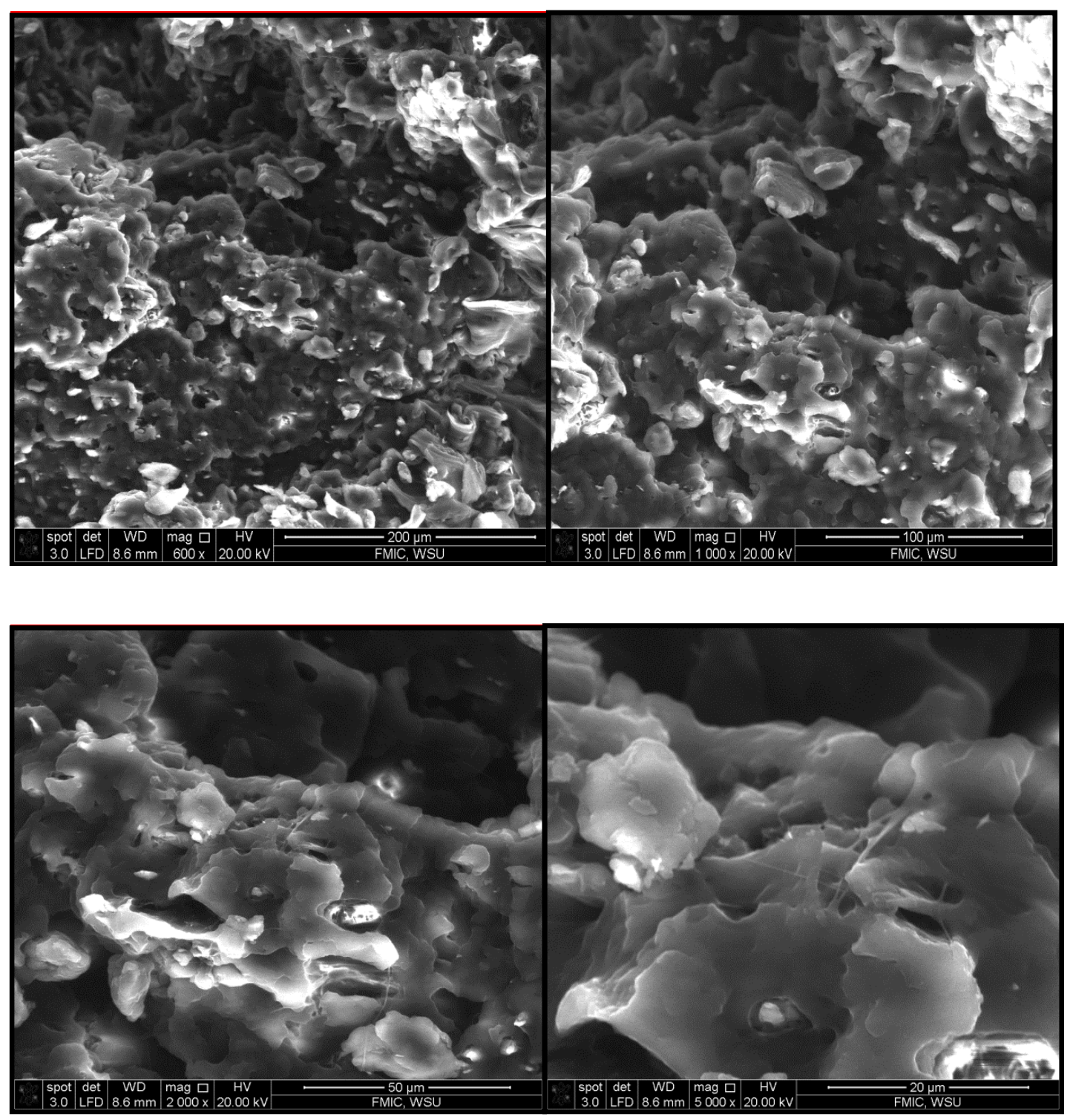

(a)

Figure 8. Cont. 

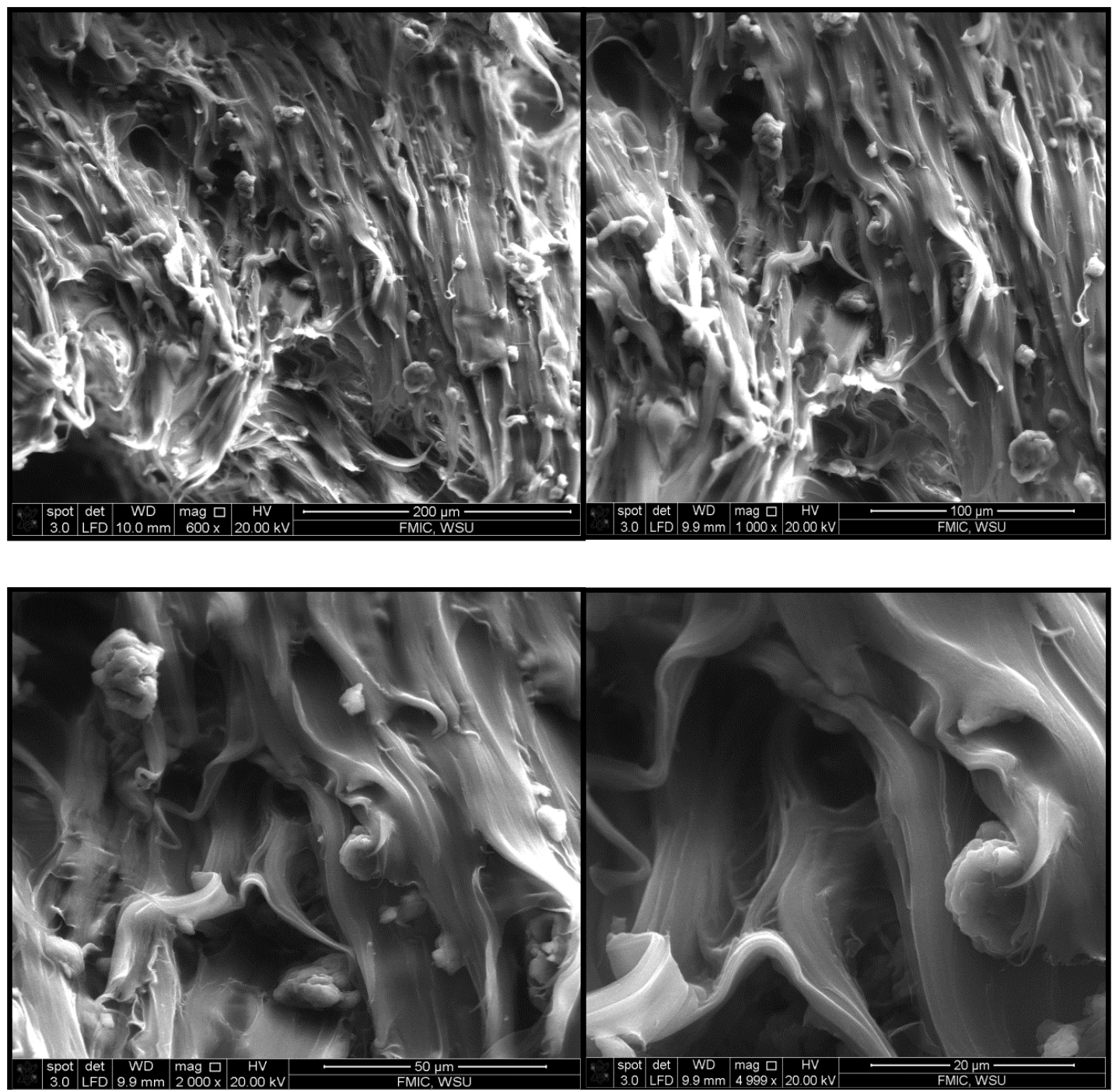

(b)

Figure 8. (a) SEM micrographs of the fracture surfaces of $20 \mathrm{wt} \%$ powdered cellulose/PP composites, S4-Co, extended at $5.08 \mathrm{~mm} / \mathrm{min}$. (b) SEM micrographs of the fracture surfaces of $20 \mathrm{wt} \%$ powdered cellulose/PP composites, S4-4_Co, extended at $5.08 \mathrm{~mm} / \mathrm{min}$.

Given these results, we infer that the incompatibility of the environments of cellulose polar functional groups and the non-polar PP matrix is the primary driving force governing the fracture mode and matrix yielding in the S4_Co composite at a 5.08-mm/min testing speed.

\section{Conclusions}

The reinforcing capacity of powdered cellulose in polypropylene composites was analyzed in terms of both thermal and tensile properties, with particular attention to the effect of the cellulose reducing ends. Our results indicate that the thermal and tensile properties of the powdered cellulose/polypropylene system can be improved through effective reduction of cellulose reducing ends, thus allowing the development of satisfactory interfacial cellulose fiber/matrix adhesion, and opening possibilities for the manufacture of composites with the appropriate degradability potential and performance in service.

Author Contributions: Conceptualization, M.A.; Methodology, M.A.; Validation, M.A. and M.P.W.; Formal Analysis, M.A.; Investigation, M.A. and M.R.G.; Resources, M.P.W.; Writing-Original Draft Preparation, 
M.A. and M.R.G.; Writing-Review \& Editing, M.A. and M.P.W.; Supervision, M.P.W. and M.A.; Project Administration, M.P.W. and M.A.; Funding Acquisition, M.P.W.

Acknowledgments: This material is based on work supported by National Science Foundation-Center for Bioplastics and Biocomposites (NSF-CB ${ }^{2}$ IUCRC) under Grant No. 1439732. The authors would like to acknowledge the Franceschi Microscopy and Imaging Center (FMIC) at Washington State University for providing SEM facility.

Conflicts of Interest: The authors declare no competing financial interest.

\section{References}

1. Rozman, H.D.; Sobra-Mulisa, A.; Tay, G.S. A comparison study of lignocellulosic-thermoplastic composites prepared from different compounding techniques. J. Appl. Polym. Sci. 2012, 124, 4547-4553. [CrossRef]

2. English, B.; Chow, P.; Bajwa, D.S. Processing Into Composites; CRC Press, Inc. Lewis Publishers: Boca Raton, FL, USA, 1997.

3. Maddah, H.A. Polypropylene as a Promising Plastic: A Review. Am. J. Polym. Sci. 2016, 6, 1-11.

4. Mohammed, L.; Ansari, M.N.M.; Pua, G.; Jawaid, M.; Islam, M.-S. A review on natural fiber reinforced polymer composite and its applications. Int. J. Polym. Sci. 2015, 2015, 243947. [CrossRef]

5. Faruk, O.; Jimi, T.; Mohini, S. Lightweight and Sustainable Materials for Automotive Applications; Faruk, O., Jimi, T., Mohini, S., Eds.; CRC Press: Boca Raton, FL, USA, 2017.

6. Lee, S.-H.; Wang, S.-Q.; Pharr, G.M.; Xu, H.T. Evaluation of interphase properties in a cellulose fiber-reinforced polypropylene composite by nanoindentation and finite element analysis. Compos. Part A Appl. Sci. Manuf. 2007, 38, 1517-1524. [CrossRef]

7. Luz, S.M.; Del Tio, J.; Rocha, G.J.M.; Gonçalves, A.R.; Del'Arco, A.P. Cellulose and cellulignin from sugarcane bagasse reinforced polypropylene composites: Effect of acetylation on mechanical and thermal properties. Compos. Part A Appl. Sci. Manuf. 2008, 39, 1362-1369. [CrossRef]

8. Bajpai, P. Pretreatment of Lignocellulosic Biomass for Biofuel Production; Springer: Manhattan, NY, USA, 2016; pp. 7-11.

9. Thoorens, G.; Fabrice, K.; Bruno, L.; Brian, C.; Brigitte, E. Microcrystalline cellulose, a direct compression binder in a quality by design environment-A review. Int. J. Pharm. 2014, 473, 64-72. [CrossRef]

10. Stutz, A.E.; Albert, M. Glycoscience: Epimerisation, Isomerisation and Rearrangement Reactions of Carbohydrates; Springer: Manhattan, NY, USA, 2001.

11. Mikushina, I.V.; Troitskaya, I.B.; Dushkin, A.V.; Natalia, G. Bazarnova. Changes in the chemical composition of wood during mechanochemical treatment. Chem. Sustain. Dev. 2002, 10, 441-445.

12. Saito, T.; Akira, I. TEMPO-mediated oxidation of native cellulose. The effect of oxidation conditions on chemical and crystal structures of the water-insoluble fractions. Biomacromolecules 2004, 5, 1983-1989. [CrossRef]

13. Zhou, Z.; Jaaskelainen, A.S.; Vuorinen, T. Oxidation of cellulose and carboxylic acids by hypochlorous acid: Kinetics and mechanisms. J. Pulp Pap. Sci. 2008, 34, 212.

14. Cumpstey, I. Chemical modification of polysaccharides. ISRN Org. Chem. 2013, 2013, 414672. [CrossRef]

15. Eyley, S.; Wim, T. Surface modification of cellulose nanocrystals. Nanoscale 2014, 6, 7764-7779. [CrossRef] [PubMed]

16. Clibbens, D.-A.; Bert, P.-R. 25-The tensile strength and fluidity of chemically modified cotton. J. Text. Inst. Trans. 2008, 19, 389-404. [CrossRef]

17. Zhang, B.; Leng, E.-W.; Wang, P.; Gong, X.; Zhang, J.; Zhang, Y.; Xu, M.-H. Effect of reducing ends on the pyrolysis characteristics and product distribution of cellulose. J. Anal. Appl. Pyrolysis 2015, 114, 119-126. [CrossRef]

18. Sharma, P.R.; Varma, A.J. Thermal stability of cellulose and their nanoparticles: Effect of incremental increases in carboxyl and aldehyde groups. Carbohydr. Polym. 2014, 114, 339-343. [CrossRef] [PubMed]

19. Azuma, Y.H.; Watanabe, T.S.; Nakatani, H. Outdoor and accelerated weathering tests for polypropylene and polypropylene/talc composites: A comparative study of their weathering behavior. Polym. Degrad. Stab. 2009, 94, 2267-2274. [CrossRef]

20. Xue, Y.; Veazie, D.R.; Glinsey, C.; Horstemeyer, M.F.; Rowell, R.M. Environmental effects on the mechanical and thermomechanical properties of aspen fiber-polypropylene composites. Compos. Part B Eng. 2007, 38, 152-158. [CrossRef] 
21. Abu-Sharkh, B.F.; Halim, H. Degradation study of date palm fibre/polypropylene composites in natural and artificial weathering: Mechanical and thermal analysis. Polym. Degrad. Stab. 2004, 85, 967-973. [CrossRef]

22. Roger, R.; Sandra, M.; Lange, E.; Jacobson, R.E. Weathering performance of plant-fiber/thermoplastic composites. Mol. Cryst. Liq. Cryst. 2000, 353, 85-94. [CrossRef]

23. Ribeiro, L.S.; Órfão, J.J.M.; Pereira, M.-F.R. Enhanced direct production of sorbitol by cellulose ball-milling. Green Chem. 2015, 17, 2973-2980. [CrossRef]

24. Paakkari, T.; Serimaa, R.; Fink, H.-P. Structure of amorphous cellulose. Acta Polym. 1989, 40, 731-734. [CrossRef]

25. Jiang, J.-X.; Wang, J.-W.; Zhang, X.; Michael, W. Evaluation of physical structural features on influencing enzymatic hydrolysis efficiency of micronized wood. RSC Adv. 2016, 6, 103026-103034. [CrossRef]

26. Benedict, S.R. A reagent for the detection of reducing sugars. J. Biol. Chem. 1909, 5, 485-487.

27. Kongruang, S.; Penner, M.H. Borohydride reactivity of cellulose reducing ends. Carbohydr. Polym. 2004, 58, 131-138. [CrossRef]

28. Azadfar, M.; Gao, A.-H.; Bule, M.V.; Chen, S. Structural characterization of lignin: A potential source of antioxidants guaiacol and 4-vinylguaiacol. Int. J. Biol. Macromol. 2015, 75, 58-66. [CrossRef]

29. Khalil, H.P.S.A.; Ismail, H.; Rozman, H.D.; Ahmad, M.N. The effect of acetylation on interfacial shear strength between plant fibers and various matrices. Eur. Polym. J. 2001, 37, 1037-1045. [CrossRef]

30. Bodirlau, R.; Teaca, C.A. Fourier transform infrared spectroscopy and thermal analysis of lignocellulose fillers treated with organic anhydrides. Rom. J. Phys. 2009, 54, 93-104.

31. Srinivasa, M.S.; Manonmani, K. Fabrication and characterization of $\mathrm{TiO} 2$ particulate filled glass fiber reinforced polymer composite. Mater. Phys. Mech. 2013, 18, 28-34.

32. Sclavons, M.; Laurent, M.; Devaux, J.; Carlier, V. Maleic anhydride-grafted polypropylene: FTIR study of a model polymer grafted by ene-reaction. Polymer 2005, 46, 8062-8067. [CrossRef]

33. Kazayawoko, M.; Balatinecz, J.J.; Woodhams, R.T. Diffuse reflectance Fourier transform infrared spectra of wood fibers treated with maleated polypropylenes. J. Appl. Polym. Sci. 1997, 66, 1163-1173. [CrossRef]

34. Kim, H.-S.; Lee, B.-H.; Choi, S.-W.; Kim, S.; Kim, H.-J. The effect of types of maleic anhydride-grafted polypropylene (MAPP) on the interfacial adhesion properties of bio-flour-filled polypropylene composites. Compos. Part A Appl. Sci. Manuf. 2007, 38, 1473-1482. [CrossRef]

35. Sharma, H.S.S.; Kernaghan, K. Thermogravimetric analysis of flax fibres. Thermochim. Acta 1988, 132, 101-109. [CrossRef]

36. Wang, Z.-H.; McDonald, A.G.; Westerhof, R.J.M.; Kersten, S.R.A.; Cuba-Torres, C.M.; Ha, S.; Pecha, B.; Garcia-Perez, M. Effect of cellulose crystallinity on the formation of a liquid intermediate and on product distribution during pyrolysis. J. Anal. Appl. Pyrolysis 2013, 100, 56-66. [CrossRef]

37. Joseph, P.V.; Marcelo, S.; Rabello, L.H.C.; Joseph, M.-K.; Thomas, S. Environmental effects on the degradation behaviour of sisal fibre reinforced polypropylene composites. Compos. Sci. Technol. 2002, 62, 1357-1372. [CrossRef]

38. Davis, A.; David, S. Weathering of Polymers; Springer Science \& Business Media: Berlin, Germany, 1983.

39. Miyazaki, K.; Kyosuke, M.; Noriyasu, O.; Minoru, T.; Hisayuki, N. Cellulose/polypropylene composites: Influence of the molecular weight and concentration of oxidatively degraded and maleated polypropylene compatibilizers on tensile behavior. J. Appl. Polym. Sci. 2009, 111, 1835-1841. [CrossRef]

40. Narisawa, I. Crazing and shear yielding in polypropylene. In Polymer Science and Technology Series; Karger-Kocsis, J., Ed.; Springer: Dordrecht, Germany, 1999; pp. 124-127.

41. Coutinho, F.; Costa, T.; João Carlos, S.; Daniele, M. Sawdust reinforced polypropylene composites: A study of fracture behavior. Polym. Test. 2000, 19, 625-633. [CrossRef]

42. Omrani, E.; Menezes, P.L.; Rohatgi, P.K. State of the art on tribological behavior of polymer matrix composites reinforced with natural fibers in the green materials world. Eng. Sci. Technol. Int. J. 2016, 19, 717-736. [CrossRef]

(C) 2019 by the authors. Licensee MDPI, Basel, Switzerland. This article is an open access article distributed under the terms and conditions of the Creative Commons Attribution (CC BY) license (http://creativecommons.org/licenses/by/4.0/). 